ПРИЛОЗИ, Одделение за природно-математички и биотехнички науки, МАНУ, том 38, бр. 1, стр. 13-16 (2017)

CONTRIBUTIONS, Section of Natural, Mathematical and Biotechnical Sciences, MASA, Vol. 38, No. 1, pp. 13-16 (2017)

Received: July 26, 2016

ISSN 1857-9027

Accepted: March 03, 2017

e-ISSN 1857-9949

UDC: $001.3: 316.7$

DOI:10.20903/csnmbs.masa.2017.38.1.96

Overview

Thinking about a suitable topic to be put at the opening pages of this special issue dedicated to the $80^{\text {th }}$ anniversary of academician Bojan Soptrajanov, we deemed more than appropriate to place the thought provoking overview of a big friend of Macedonia and the Ss. Cyril and Methodius University in Skopje, our honorary professor James Trefil, a Clarence Robinson Professor of Physics, from the George Mason University in Fairfax, Virginia. Prof. Trefil is a great scientist and even greater educator (the latter is known to anyone that has read at least one of the 50+ books written by him). The overview is on the (always relevant) topics like science, science education, science teaching and scientific literacy, as a need in a truly democratic society.

\title{
SCIENCE EDUCATION AND THE TWO CULTURES ${ }^{\bullet}$
}

\author{
James Trefil \\ Clarence J Robinson Professor of Physics, George Mason University, \\ Fairfax, Virginia, USA \\ e-mail: jtrefil@gmu.edu
}

In 1959 the British scientist, novelist, and government official C.P. Snow (1905-1980) gave the prestigious Rede Lecture at Cambridge University. His argument, which has come to be known as the 'Two Cultures' view, was that the academic world was divided into two non-overlapping camps which he characterized as the scientific and the literary cultures. He argued that while scientists generally have some background in the humanities - how many scientists do you know, for example, that have never seen or read a play by Shakespeare?-literary types generally know little about science. In what is perhaps the most famous passage in his book, he recounts the experience of listening to literary types going on about the illiteracy of scientists and then asking "How many of you can tell me what the Second Law of thermodynamics is?" He was, as you might expect, met by a thundering silence.

Approaching the Two Cultures divide from the science side, there is a question that comes naturally to the mind of someone involved in science education: given that we want to provide those in the literary culture with some knowledge of science what, exactly, is the kind of science we need to teach? What, in other words, do scientists need to do to help our colleagues learn enough about what we do to help erase the chasm that Snow spoke about almost 60 years ago? In what follows, I will address this question from the point of view of the American educational system.

There is, in fact, a long tradition of thought on the issue of science education in America. Like almost everything else in American educational philosophy, it can be traced back to John Dewey (1859-1952). At the opening of the twentieth century, he wrote:

Contemporary civilization rests so largely upon applied science that no one can really understand it who does not grasp something of the scientific method... on the other hand, a consideration of scientific resources and achievements from the standpoint of their application to the control of industry, transportation (and) communication, not only increases the future social efficiency of those instructed, but augments the immediate vital appeal and interest of the subject....

Dewey summarized his philosophy this way:

- Dedicated to academician Bojan Šoptrajanov on the occasion of his $80^{\text {th }}$ birthday 
The formation of scientific habits of mind should be the primary aim of the science teacher in the high school

A word of explanation: in 1910, when Dewey wrote these words, fewer than $10 \%$ of Americans actually finished high school (i.e. remained in school to age 18). To translate this directive to modern times, then, you would probably want to substitute "high end university" for "high school" in the above.

But regardless of the level of students we're talking about, Dewey's notion of imparting a 'scientific habit of mind' has carried through ever since it was first uttered. It would, I think, be the consensus view of scientists today, as it was back in 1910. In the words of Nobel Laureate Carl Weiman,

\section{We want them to think like us}

Another way of characterizing this approach to science education is to say that the goal of providing science education should be to produce miniature scientists-people who can do, in a limited way, what scientists do. Leaving aside the question of whether this goal is actually attainable - and I have grave reservations on that score - we can ask whether it is desirable. Is this really the best use of the limited time available for us to teach non scientists?

I suggest that it is not. In the spirit of this festschrift, in fact, I would propose another goal:

Students should know as much about science as they do about Shakespeare

Or, in a sentence I often use when I want to annoy my colleagues,

Students should be able to read the newspaper on the day they graduate

The traditional goal enunciated by Dewey is basically a requirement that students be able to $d o$ science at some level. This is the goal that I am arguing is inappropriate. To make this point, let me take an example from my own education. At the university I took a number of courses with names like "music appreciation" and "introduction to renaissance art". These courses enriched my life immeasurably, which is easy enough to understand. What they did not do, however, was demand that I be able to play a musical instrument or create a painting. Instead, they gave me the background I needed to make judgments about music and works of art without asking that I actually to what musicians and artists do.

To make this point crystal clear, let me point out that as a lifelong opera buff, I feel perfectly qualified to decide whether the tenor did or did not do a good job on his marvelous first act aria in $L a$ Boheme, even though I would never dream of trying to perform that aria myself. I would suggest that a similar approach to science education for nonscientists is more appropriate that wanting them to acquire a 'scientific habit of mind'.

Having said this let me make a brief diversion to talk about a subject that often arises at this point. Given that we want students to 'appreciate' science the way they appreciate music, should we teach them about what we know of the way the world operates or should be instead emphasize the way that knowledge is gained? Should we, in other words, emphasize content or method?

Unfortunately, the debate on this issue often involves setting up straw men ("You just want them to memorize facts" or "You can't think critically about a subject you know nothing about."). My own view is that everyone can be placed somewhere on a method-content continuum, with few people at either extreme. As will be clear from what follows, I locate myself rather more toward the content end of the spectrum, because I believe that that better serves the achievement of scientific literacy. Having said this, I hasten to add that I believe that the correct answer to the question of content vs. method is 'yes'. Some mix of the two is necessary for scientific literacy but, as I shall argue below, I think the weight of the educational system should be on the content side. We want our students to have a wide acquaintance with the scientific worldview, and this is not something that can be acquired by learning about something called the 'scientific method'. I would, in fact, suggest yet another general rule we can adopt:

If you expect a student to know something, you should tell him or her what it is

Teaching students about mechanics by having them roll balls down inclined planes may indeed impart something about the scientific method, but it won't help them grapple with an issue like stem cell research, any more than learning French will help them understand Chinese. To argue otherwise is to advocate what I call the "teach them relativity and they'll derive molecular biology on the way home" school of thought.

One way to approach the issue of the proper goal of science education is to ask ourselves how students will encounter science in later life. A cursory glance at a newspaper or a magazine shows that science will always come up in a way that is (1) multidisciplinary, and (2) part of a much larger issue. The global warming discussion, for example, involves many branches of science, but quickly moves 
into areas of economics, law, international relations, and ethics. The science, then, serves as an entry pass into the wider debate and is not an end in itself.

I often find is useful to think about scientific literacy in terms of a broader concept called cultural literacy. Cultural literacy is defined as the knowledge that people, in a given place and at a given time, assume other people possess. Americans, for example, will use a term like "World Series" or "Wall Street" without explaining what they mean because they assume the person to whom they are speaking already knows what they are. The sum of all these unspoken assumptions comprises cultural literacy. In passing, I should note that the acquisition of cultural literacy would be an admirable goal for the entire educational system.

Scientific literacy is that part of cultural literacy that deals with science and technology. It is important to understand that, while the rationale for needing to know the content of other parts of cultural literacy revolves around the fact that other people make assumptions about your knowledge, the rationale for scientific literacy is slightly different. I will define scientific literacy as what you need to know to enter the kind of science-tinged public debates discussed above.

When it comes to scientific literacy, we are in a classic good news-bad news situation. The good news is that scientists are pretty much in agreement about what the important parts of science are-you'd have to look a long time, for example, to find someone who wanted to exclude Newton's Laws of Motion from the list of essential scientific principles. The bad news is that we've done a pretty poor job of producing a scientifically literate population. Considering the data on American scientific literacy that has been collected over the years, we see that over two thirds of Americans don't possess even the minimal amount of knowledge needed to deal with everyday issues.

Fortunately, the inherent structure of science suggests a scheme for imparting exactly this sort of knowledge. I often use the analogy of a spider web, where all the world's phenomena, from stars to microbes, are located on the outer rim. Start anywhere and begin asking questions, and you begin to move in toward the center, finding unexpected connections along the way (think of Maxwell's discovery of electromagnetic radiation as an example). At the very core of the web are a relatively small number of governing principles-I call them Great Ideasthat form the superstructure, the skeleton, on which the scientific view of the world is based. Everything in the universe, from the smallest subatomic parti- cle to the largest galactic cluster, operates according to these laws. This means that the matrix of knowledge represented by the Great Ideas is an ideal framework that out students can use to deal with public issues, since anything they are likely to encounter will involve some subset of these laws.

For reference, here are the Great ideas as given in one reference:

\section{The Universe is Regular and Predictable}

The energy of a closed system is conserved

Heat will not flow spontaneously from a cold to a hot body

\section{Maxwell's Equations}

\section{Matter is made from atoms}

The properties of materials depend on the identity, arrangement, and binding of the atoms of which it is made

In the quantum world, you cannot measure an object without changing it

The laws of nature are the same in all frames of reference nucleus

There is a great deal of energy in the atomic

The nucleus is made of particles, which are made of quarks......

Stars live and die like everything else

The universe began in a hot, dense state about 14 billion years ago and has been expanding ever since

The surface of the Earth is constantly changing

The Earth works in cycles

Life is based on chemistry

The behavior of molecules in living systems depends on their shape

Life's chemistry is coded for in DNA

All living thing share the same genetic code selection

Life evolved through the process of natural

In addition to their universality, there is another aspect of modern science, seldom discussed, that argues in favor of a Great Ideas approach to science education and scientific literacy. The fact of the matter is that science has changed in a fundamental way over the last 50 years, a way that has yet to be incor- 
porated into educational thinking. The cause of the change is simple: the advent of the digital computer.

Look at it this way: from Isaac Newton on, the progress of science was governed by the ability to do pencil-and-paper mathematics. A seemingly simple question like "Will the planets in the solar system ever occupy the same positions they do now?" involves so many variables (the positions and speeds of the planets, their moons, the larger asteroids, etc.) that the question couldn't be answered with the mathematical techniques available at the time, and, indeed, regular prizes were awarded to scientists who developed techniques for approximating the answer. Later on, when major astronomical observatories in Europe and North America began accumulating mounds of data, they hired teams of human beings (usually women) to analyze it. Interestingly enough, these people were called 'computers'.

Up until the middle of the twentieth century, in other words, scientists concentrated on describing relatively simple systems - systems that could be analyzed by hand. The advent of the digital computer changed all that. For the first time in history, the growing power of the computer could be used to analyze every more complex systems, from trans-sonic flow over an airfoil (the 747 was the first airplane to be designed by computer) to, today, gene networks and global climate. And this development, in turn, has changed the way that science presents itself to the average citizen.
Take global warming as an example. The primary tool in climate prediction is the so-called global circulation model (GCM). These giant computer programs, monuments to human ingenuity, try to incorporate all the different phenomena that can influence the climate. For example, they have to account for the effects of sea ice, since ice reflects sunlight while water absorbs it. They have to deal with vegetation, aerosols, clouds, and everything else that might be important. As a result, there probably isn't an individual on the planet who really understands everything that these models do. Furthermore, most $\mathrm{PhD}$ scientists have no more ability to judge the output of these models than does the average citizen-being an expert in string theory or molecular genetics just isn't going to get you very far in analyzing claims based on GCM calculations.

So what does it mean to talk about a 'scientific habit of mind' in this kind of situation? Measuring the melting of an ice cube or keeping weather record for a few months-the sorts of activities often associated with teaching the scientific method-isn't going to help much in understanding climate change. I would suggest, instead, that the best way to equip our students to deal with the world they will be living in is to give them the intellectual superstructure embodied in the Great Ideas, instill in them an appreciation of the world's complexity, and let them work things out for themselves. 